\title{
Impact of Commuting Mode on Obesity Among a Working Population in Beijing, China: Adjusting for Air Pollution
}

This article was published in the following Dove Press journal: Diabetes, Metabolic Syndrome and Obesity: Targets and Therapy

\author{
Yue Liu ${ }^{1,2, *}$ \\ Lixin Tao ${ }^{1,2, *}$ \\ Jie Zhang ${ }^{1,2}$ \\ Jia Liu ${ }^{1,2}$ \\ Haibin $\mathrm{Li}^{1,2}$ \\ Xiangtong Liu ${ }^{1,2}$ \\ Yanxia Luo ${ }^{1,2}$ \\ Jingbo Zhang ${ }^{3}$ \\ Wei Wang $\mathbb{1}^{4}$ \\ Xiuhua Guo ${ }^{1,2}$ \\ 'Department of Epidemiology and Health \\ Statistics, School of Public Health, Capital \\ Medical University, Beijing, People's \\ Republic of China; ${ }^{2}$ Beijing Municipal Key \\ Laboratory of Clinical Epidemiology, \\ Capital Medical University, Beijing, \\ People's Republic of China; ${ }^{3}$ Beijing \\ Physical Examination Center, Beijing, \\ People's Republic of China; ${ }^{4}$ Global \\ Health and Genomics, School of Medical \\ Sciences and Health, Edith Cowan \\ University, Perth, Western Australia, \\ Australia \\ *These authors contributed equally to \\ this work
}

Background: Few studies have considered the interplay between commuting mode and air pollution on obesity. The aim of this study was to examine whether workplace air pollutants exposure modifying the associations between different commuting mode and obesity.

Methods: A cross-sectional study of workers in Beijing was conducted in 2016. The study sample comprised 10,524 participants aged 18 to 65 years old. Outcomes were defined as overall obesity (BMI $\geq 28 \mathrm{~kg} / \mathrm{m}^{2}$ ) and abdominal obesity (WC $\geq 85 \mathrm{~cm}$ in men and $\mathrm{WC} \geq 80 \mathrm{~cm}$ in women). Commuting modes were divided into walking, cycling, bus, subway, and car or taxi. Logistic regression models were used to estimate odds ratios relating commuting mode to overall and abdominal obesity and stratified by gender, controlling for covariates.

Results: The association between commuting mode and obesity was more strongly in men than women. In the fully adjusted models, compared with car or taxi commuters, cycling (men: $\mathrm{OR}=0.37,95 \% \mathrm{CI}=0.20$ to 0.68 ) or bus (men: $\mathrm{OR}=0.58,95 \% \mathrm{CI}=0.36$ to 0.94 ) counterparts had a lower risk of overall obesity. Compared with car or taxi commuters, walking (men: $\mathrm{OR}=0.57,95 \% \mathrm{CI}=0.36$ to 0.91 ), bus (men: $\mathrm{OR}=0.59,95 \% \mathrm{CI}=0.39$ to 0.89 ), or subway (men: $\mathrm{OR}=0.59,95 \% \mathrm{CI}=0.39$ to 0.89 ) counterparts had a lower risk of abdominal obesity. We observed significant interactions between exposure $\mathrm{PM}_{10}$ and cycling on overall obesity in men. After adjusting for air pollutants, the association between commuting mode and obesity was slightly strengthened.

Conclusion: This study findings indicate that active (walking or cycling) or public (bus or subway) commuting modes were protected factors for overall and abdominal obesity among men. Air pollutants do not obscure the benefits of active or public commuting for obesity. These associations support the policy for increasing active or public commuting as a strategy to reduce the prevalence of obesity.

Keywords: obesity, commuting mode, air pollutant, body mass index, waist circumference, office worker

\section{Plain Language Summary What is Already Known About This Subject?}

It is well known that physical activity is beneficial for health. Active commuting (walking, cycling) as a form of physical activity is associated with lower risk of obesity. The scientific evidence on commuting mode or air pollutants in relation to risk of obesity is not entirely consistent. Little is known about the association between commuting mode and obesity, after adjusted for the effects of air pollutants. 


\section{What are the New Findings?}

Men office worker had a higher prevalence of obesity than women, especially abdominal obesity. Considering the effects of air pollutants, a steady negative association between active (walking, cycling) or public (bus, subway) commuting mode and obesity, while these associations were only found in men.

\section{How Might This Impact on Policy or Clinical Practice in the Foreseeable Future?}

Increasing active (walking, cycling) or public (bus, subway) commuting as a strategy to reduce the prevalence of obesity and improve public health.

\section{Introduction}

Obesity has become a pandemic in China, ${ }^{1,2}$ and it is one of the major risk factors for noncommunicable chronic diseases (NCDs), such as cardiovascular disease (CVD), ${ }^{3}$ metabolic disorders, and premature mortality. ${ }^{4-6}$ Over half of the Chinese population is overweight or obese, and in mega-cities such as Beijing, overweight and obesity have always been serious problems. ${ }^{7,8}$ With the rapid economic development of China, great changes have taken place in the lifestyle and physical activity habits of the inhabitants. ${ }^{8}$ Among these changes, multiple factors such as lack of physical activity, unhealthy lifestyles, working stress, and environmental pollution may contribute to increased obesity and NCDs. ${ }^{2,9,10}$

Air pollution, especially particulate matter with an aerodynamic diameter smaller than $10 \mu \mathrm{m}\left(\mathrm{PM}_{10}\right)$ or 2.5 $\mu \mathrm{m}\left(\mathrm{PM}_{2.5}\right)$, has been improving in recent years but in winter is worsening in Beijing. ${ }^{11}$ Beijing is a crowded metropolis where traffic emissions account for a large share of $\mathrm{PM}_{2.5}$ concentration. ${ }^{12}$ The working population is a subtype of population. They faced the heavy traffic, life insecurity and heavy work pressure in Beijing, making them more prone to developing obesity. Physical activity is important for office employees, especially for those who are exposed to the harmfulness of sedentary work. ${ }^{13}$ Integrating physical activity into daily life is recognized as a potential way to prevent obesity and chronic diseases. ${ }^{14,15}$ Active commuting, which refers to walking and cycling, is positively correlated with the benefits of physical activity. ${ }^{16}$ Nationwide, active commuting is promoted as a way of incorporating physical activity into daily life to reduce the rates of NCDs. ${ }^{16}$ There are quite a few confounding factors in the associations between different commuting modes and obesity, and some uncertainties about the associations still exist. Exposure to traffic microenvironments was reported to be associated with some health risks such as obesity and cardiopulmonary diseases. ${ }^{17-20}$ In addition, air pollution is associated with inflammation around the bronchi, which may increase systemic inflammation and oxidative stress leading to obesity. $^{21}$ Animal experiments showed that air pollution can lead to weight gain and cardiorespiratory and metabolic dysfunction. ${ }^{22}$

Previous studies have consistently suggested that walking or cycling commuters have lower BMIs than car commuters $^{23-26}$ and that exposure to air pollutants associated with inflammatory adipokines derangements ${ }^{27}$ and adverse health outcomes. ${ }^{28,29}$ Some studies have shown that active commuting should not be limited to walking and cycling but should also include public transportation. $^{25,30}$ In Beijing, many people live too far from the workplace to commute by walking or cycling. During rush hour, traffic congestion and bad weather conditions such as haze can occur. However, most studies have not accounted for the impact of air pollutants on the relationship between commuting mode and health outcomes. Thus, the aim of this research was to investigate the association between commuting mode and overall and abdominal obesity in a sample of Chinese working adults after adjustment for air pollutants and other potential confounders.

\section{Materials and Methods Study Design and Data Collection}

The study was conducted to provide cross-sectional estimates of the association between obesity and commuting mode among the employees of various enterprises and institutions, which included state-owned enterprises, private enterprises and public institutions. Participants attended health examinations at the Beijing physical examination center. The participants included 11,474 individuals who were recruited via a convenience sampling method from 69 enterprise and public institutions in 7 districts (Chaoyang, Dongcheng, Fengtai, Haidian, Xicheng, Daxing, and Pinggu) in Beijing in 2016. Additional 950 individuals were excluded due to retirement, missing data or the presence of CVD, cerebrovascular disease, or cancer. Finally, 10,524 subjects were included in this research. Figure S1 illustrated a flowchart of the selection of the study subjects. The 
research was approved by the Ethics Committee of Capital Medical University (NO: 2013SY26) and conducted in accordance with the Declaration of Helsinki. Written informed consent was obtained from all the participating subjects prior to data collection.

The subjects received health examinations at the Beijing physical examination center by experienced doctors. Height and body weight were measured while the participant was barefoot and wearing minimal clothing. Body mass index (BMI) was calculated using the standard equation weight $(\mathrm{kg}) /$ height $(\mathrm{m})^{2}$. Waist circumference (WC) was measured at the midway point between the top of the hipbone and the bottom of the ribs.

Demographic data were obtained by a questionnaire. The questionnaire was investigated by two trained investigators. Participants were asked, "What is the main type of transport that you often use to get to and from work?" Participants were allowed to select one of the following options: walking, cycling, bus, subway, and car or taxi. There was also some information on lifestyle factors: education level, self-reported work pressure, intensity of physical activity, frequency of physical activity, sleep duration, smoking status, alcohol consumption status, dietary habits, grain consumption, medical history of hypertension, and medical history of diabetes. Current or previous smoking was defined as an adult who has smoked 100 cigarettes in his or her lifetime and who currently smokes cigarettes or had quit smoking at the time of interview. Current or previous drinking was defined as at least 12 drinks in any one year in lifetime or had quit drinking at the time of interview. Excessive meat intake was defined as at least once a week daily intake of $75 \mathrm{~g}$ or more of meat. Excessive edible oil intake was defined as at least once a week daily intake of $30 \mathrm{~g}$ or more of edible oil. Excessive salt intake was defined as at least once a week daily intake of $6 \mathrm{~g}$ or more of salt. Excessive sweet food intake was defined as at least once a week daily intake of $25 \mathrm{~g}$ or more of sugar.

Concentrations of air pollutants, including carbon monoxide $(\mathrm{CO})$, nitrogen dioxide $\left(\mathrm{NO}_{2}\right)$, ozone $\left(\mathrm{O}_{3}\right)$, $\mathrm{PM}_{10}, \mathrm{PM}_{2.5}$ and sulfur dioxide $\left(\mathrm{SO}_{2}\right)$, were measured at the fixed-site monitoring stations closest to the participants' workplaces. All air pollutant data were obtained from a website platform (http://zx.bjmemc. com.cn/) by the Beijing Environmental Protection Bureau (BEPB). Excluded the outliers in the hourly measured values of each monitoring station, the average annual concentration of each air pollutant was calculated by the average daily concentration of each air pollutant. Considering that obesity is a chronic disease and the long-term effect of air pollutants on health, the annual average concentrations of air pollutants collected during the year prior to the participant's physical examination were used.

\section{Outcomes}

Obesity is defined as abnormal or excessive fat accumulation that may impair health. For adults, the Chinese standard of overall obesity was defined as a BMI greater than or equal to $28 \mathrm{~kg} / \mathrm{m}^{2}$. Abdominal obesity was defined as $\mathrm{WC} \geq 85 \mathrm{~cm}$ in men and $\geq 80 \mathrm{~cm}$ in women. ${ }^{31}$

\section{Statistical Analysis}

The characteristics of the participants are presented as the mean with the standard deviation (SD) or the median with the interquartile range (IQR) for quantitative variables or with a percentage for categorical variables. The associations between the commuting mode and overall and abdominal obesity were explored using logistic regression analyses (overall obesity, no/yes; abdominal obesity, no/yes), resulting in an odds ratio (OR) with a 95\% confidence interval (95\% CI). Considering the high correlation among air pollutants (Table S1), we only keep $\mathrm{PM}_{10}$ in model 3. The results of other pollutants were shown in Table S3 and S4. Model 1 was unadjusted. In model 2 , we adjusted for age, gender, education, commuting time per day, self-reported work stress, physical activity frequency and intensity, sleep duration, smoking status, alcohol consumption status, proportion of meat and vegetable intake, dietary preferences and medical history of hypertension and diabetes. Model 3 was additionally adjusted for $\mathrm{PM}_{10}$ exposure. We added an interact term on model 3 to test the interaction between air pollutant and commuting mode.

To examine whether any associations were modified by leisure-time physical activity frequency or intensity, we performed sensitivity analyses stratified by leisure-time physical activity frequency or intensity.

All statistical analyses were carried out with the SAS software package (version 9.4; SAS Institute, Inc.). Statistical significance was indicated by a two-tailed $P$ value less than 0.05 .

\section{Results}

Figure 1 shows the distribution of monitoring stations and workplaces in Beijing. The main characteristics of the study participants according to gender are summarized in 


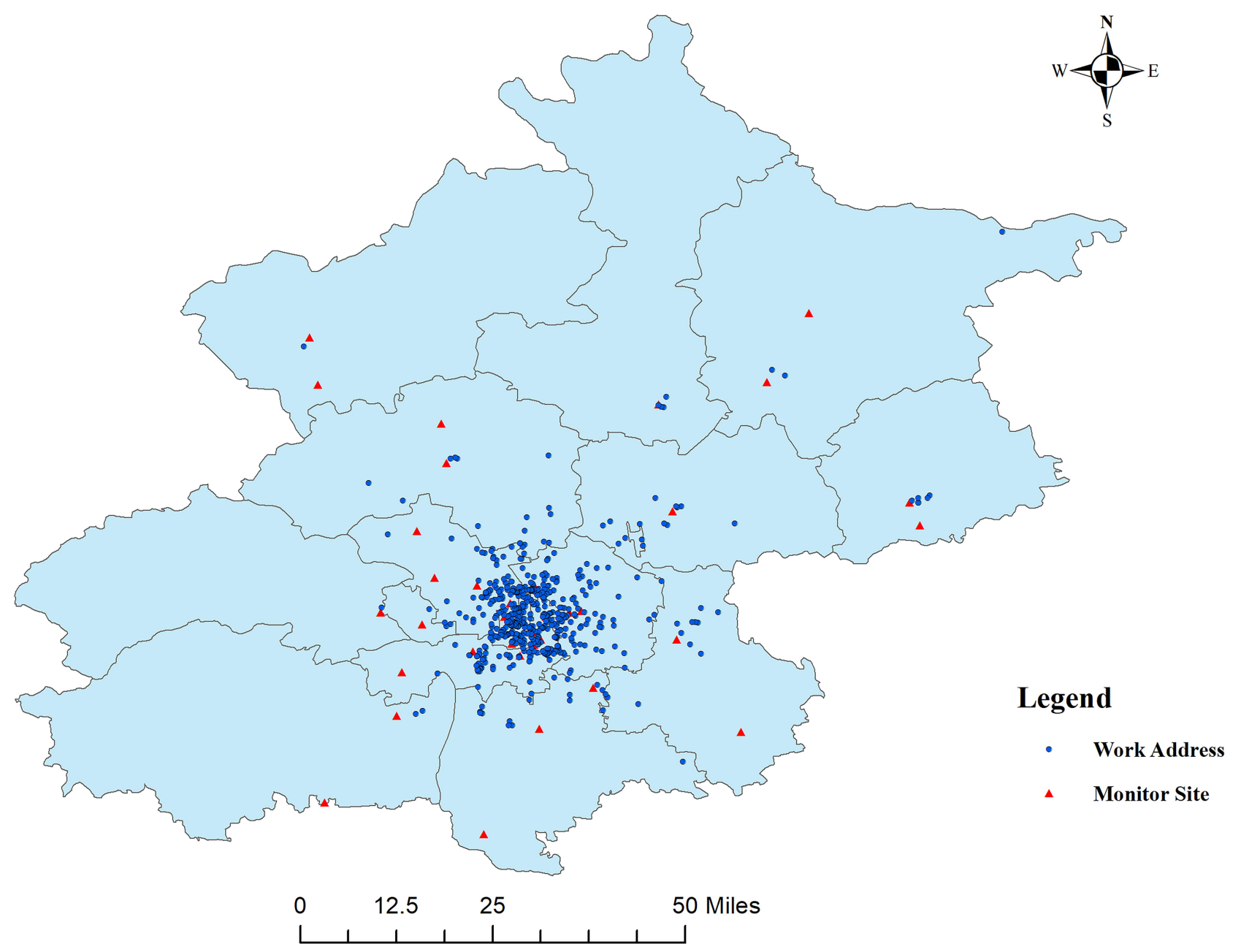

Figure I Distributions of air pollutants monitoring stations and workplaces in Beijing.

Table 1. Of the 10,524 employees of enterprises and public institutions included in this study, the most common commuting mode was car or taxi in men $(28.77 \%)$ and subway in women $(27.95 \%)$. A total of $24.97 \%$ of men chose active commuting (walking or cycling) compared with $23.31 \%$ of women. Self-reported high level of work stress was higher in men than women $(42.76 \%$ of men and $34.30 \%$ of women, $\mathrm{P}<0.0001$ ). The frequency of physical activity was slightly higher in men than women, $15.46 \%$ of men were more than once every day and $11.20 \%$ of women $(\mathrm{P}<0.0001)$, as well as the intensity of physical activity, $8.91 \%$ of men were vigorous level and $3.31 \%$ of women $(\mathrm{P}<0.0001)$. In addition, men were greater likelihood of smoking $(41.23 \%$ of men and $2.29 \%$ of women, $\mathrm{P}<0.0001)$ and drinking (61.96\% of men and $12.98 \%$ of women, $\mathrm{P}<0.0001)$ than women. In terms of diet, the proportion of excessive meat $(16.98 \%$ of men and $7.87 \%$ of women, $\mathrm{P}<0.0001)$, edible oil $(6.79 \%$ of men and
$4.06 \%$ of women, $\mathrm{P}<0.0001)$ and salt intake $(16.98 \%$ of men and $7.87 \%$ of women, $\mathrm{P}<0.0001$ ) in men were significantly greater than women, while the proportion of vegetarian $(10.57 \%$ of men and $16.31 \%$ of women, $\mathrm{P}<0.0001)$ and excessive sweet food intake $(7.94 \%$ of men and $10.71 \%$ of women, $\mathrm{P}<0.0001$ ) in women were significantly greater than men. The sleep duration was similar between men and women.

Figure 2 shows the prevalence rates of overall and abdominal obesity. In this study, 1418 (13.47\%) had overall obesity and 4712 (44.77\%) had abdominal obesity. Compared with commuters utilizing other modes, car or taxi commuters, followed by cyclists, had a higher prevalence of obesity, regardless of whether overall and abdominal obesity was being analyzed. Men employees were more likely to have obesity than women $(P<0.0001)$.

The summary statistics of air pollutants categories by commuting mode during the study period in Beijing are 
Table I The Main Characteristics of Participates for Men and Women

\begin{tabular}{|c|c|c|c|c|}
\hline Variables & Total $(n=10,524)$ & $\operatorname{Men}(n=5847)$ & Women $(n=4677)$ & $P$ value $^{a}$ \\
\hline Overall obesity & $14 \mid 8(\mid 3.47)$ & $1135(|9.4|)$ & $283(6.05)$ & $<0.0001$ \\
\hline Abdominal obesity & $47 \mid 2(44.77)$ & $3758(64.27)$ & $954(20.4)$ & $<0.0001$ \\
\hline Main commuting mode & & & & $<0.0001$ \\
\hline Car or Taxi & $2830(26.89)$ & $1682(28.77)$ & II $48(24.55)$ & \\
\hline Walking & $1356(\mid 2.88)$ & $713(12.19)$ & $643(13.75)$ & \\
\hline Cycling & $1194(11.35)$ & $747(12.78)$ & $447(9.56)$ & \\
\hline Bus & $2540(24.14)$ & $1408(24.08)$ & II $32(24.20)$ & \\
\hline Subway & $2604(24.74)$ & $1297(22.18)$ & | 307(27.95) & \\
\hline Commuting time (hour), median (IQR) & $1.9(1.60-2.00)$ & $2.00(1.90-2.00)$ & $1.90(1.00-2.00)$ & $<0.0001^{b}$ \\
\hline Age (years) & & & & $<0.0001$ \\
\hline $18-44$ & $7188(68.30)$ & $3747(64.08)$ & $344 I(73.57)$ & \\
\hline $45-65$ & $3336(31.70)$ & $2100(35.92)$ & $1236(26.43)$ & \\
\hline Education level & & & & $<0.0001$ \\
\hline High school or lower & $1336(12.69)$ & $949(16.23)$ & $387(8.27)$ & \\
\hline College & $6963(66.16)$ & $3913(66.92)$ & $3050(65.21)$ & \\
\hline Graduate or above & $2225(21.14)$ & $985(16.85)$ & $1240(26.5 \mid)$ & \\
\hline Self-reported work stress & & & & $<0.0001$ \\
\hline Low & $|58|(\mid 5.02)$ & $815(13.94)$ & $766(16.38)$ & \\
\hline Moderate & $4839(45.98)$ & $2532(43.30)$ & $2307(49.33)$ & \\
\hline High & $4104(39.00)$ & $2500(42.76)$ & 1604(34.30) & \\
\hline Physical activity frequency & & & & $<0.0001$ \\
\hline Less than once every week & $3920(37.25)$ & $2103(35.97)$ & $1817(38.85)$ & \\
\hline More than once every week & $5176(49.18)$ & $2840(48.57)$ & $2336(49.95)$ & \\
\hline More than once every day & $1428(\mid 3.57)$ & $904(15.46)$ & $524(I 1.20)$ & \\
\hline Physical activity intensity & & & & $<0.0001$ \\
\hline Mild & $5307(50.43)$ & $2676(45.77)$ & $263 \mid(56.25)$ & \\
\hline Moderate & $454 I(43.15)$ & $2650(45.32)$ & $|89|(40.43)$ & \\
\hline Vigorous & $676(6.42)$ & $52 I(8.91)$ & $155(3.31)$ & \\
\hline Sleep duration & & & & 0.2855 \\
\hline$<6$ hours/day & $7184(68.26)$ & $3966(67.83)$ & $3218(68.80)$ & \\
\hline$\geq 6$ hours/day & $3340(31.74)$ & $188 \mid(32.17)$ & $1459(31.20)$ & \\
\hline Current or previous smoking & $2518(23.93)$ & $24 I I(4 I .23)$ & $107(2.29)$ & $<0.0001$ \\
\hline Current or previous drinking & $4230(40.19)$ & $3623(61.96)$ & $607(12.98)$ & $<0.0001$ \\
\hline Vegetarian & $138 \mid(13.12)$ & $618(10.57)$ & $763(\mid 6.3 I)$ & $<0.0001$ \\
\hline Excessive meat intake & $|36|(\mid 2.93)$ & $993(16.98)$ & $368(7.87)$ & $<0.0001$ \\
\hline Excessive edible oil intake & $587(5.58)$ & $397(6.79)$ & $190(4.06)$ & $<0.0001$ \\
\hline Excessive salt intake & $2199(20.9)$ & $1449(24.78)$ & $750(16.04)$ & $<0.0001$ \\
\hline Excessive sweet food intake & $965(9.17)$ & $464(7.94)$ & $50 I(I 0.7 I)$ & $<0.000$ I \\
\hline Medication history for hypertension & $92 \mathrm{I}(8.75)$ & $676(11.56)$ & $245(5.24)$ & $<0.0001$ \\
\hline Medication history for diabetes & $195(1.85)$ & $161(2.75)$ & $34(0.73)$ & $<0.0001$ \\
\hline
\end{tabular}

Notes: Values reported as numbers (percentages), unless otherwise noted. Current or previous smoking: An adult who has smoked I00 cigarettes in his or her lifetime and who currently smokes cigarettes or had quit smoking at the time of interview. Current or previous drinking: At least 12 drinks in any one year in lifetime or had quit drinking at the time of interview. Excessive meat intake: at least once a week daily intake $75 \mathrm{~g}$ or more of meat. Excessive edible oil intake: at least once a week daily intake $30 \mathrm{~g}$ or more of edible oil. Excessive salt intake: at least once a week daily intake $6 \mathrm{~g}$ or more of salt. Excessive sweet food intake: at least once a week daily intake $25 \mathrm{~g}$ or more of sugar. ${ }^{a}$ The results of $\chi^{2}$ test, where the null hypothesis was that the difference between men and women group was equal to $0 .{ }^{b} T h e$ results of non-parametric test, where the null hypothesis was that the difference between men and women group was equal to 0 . 

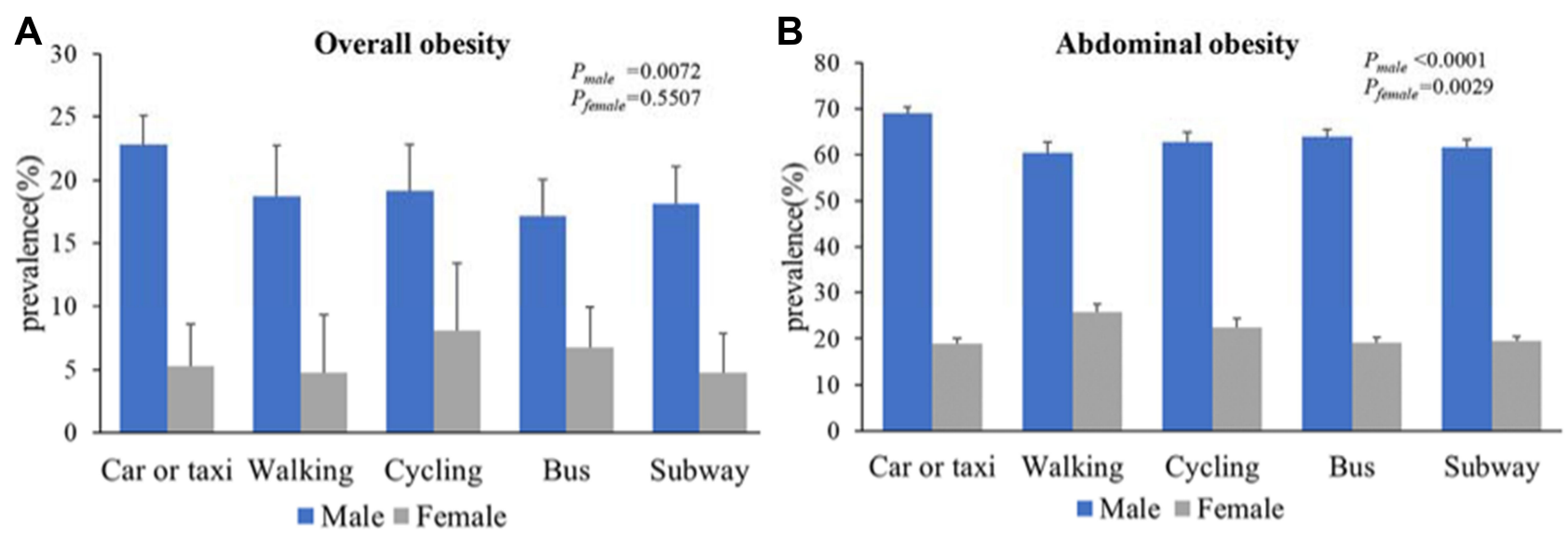

Figure 2 Prevalence of overall and abdominal obesity among the study participants. (A) Prevalence of overall obesity by commuting mode stratified by gender. (B) Prevalence of abdominal obesity by commuting mode stratified by gender.

Abbreviations: $P_{\text {male }}$, the P-value for differences in prevalence of overall or abdominal obesity with different commuting mode among men; $P_{\text {female }}$, the $P$-value for differences in prevalence of overall or abdominal obesity with different commuting mode among women.

shown in Table S2. The means (SDs) of the air pollutants were $1.19(0.22) \mathrm{mg} / \mathrm{m}^{3}$ for $\mathrm{CO}, 48.18(14.76) \mu \mathrm{g} / \mathrm{m}^{3}$ for $\mathrm{NO}_{2}, 40.66(10.24) \mu \mathrm{g} / \mathrm{m}^{3}$ for $\mathrm{O}_{3} ; 97.60(15.52) \mu \mathrm{g} / \mathrm{m}^{3}$ for $\mathrm{PM}_{10}, 73.97(11.42) \mu \mathrm{g} / \mathrm{m}^{3}$ for $\mathrm{PM}_{2.5}$ and $11.18(2.82) \mu \mathrm{g} /$ $\mathrm{m}^{3}$ for $\mathrm{SO}_{2}$.

Figure 3 shows the associations of the commuting modes with overall obesity after adjusting for potential confounders. In the overall obesity analysis in men, without adjusting for any confounders, compared with car or taxi commuters, walking, cycling, bus and subway commuters had an adjusted odds ratio of $0.70(95 \% \mathrm{CI}=0.56$ to 0.88), 0.80 (95\% $\mathrm{CI}=0.64$ to 0.99$), 0.82(95 \% \mathrm{CI}=0.68$ to
0.97 ) and 0.77 (95\% $\mathrm{CI}=0.64$ to 0.92$)$, respectively. In men, after adjusting for demographic, health and behavioral factors, walking ( $\mathrm{OR}=0.72,95 \% \mathrm{CI}=0.57$ to 0.91$)$, cycling $(\mathrm{OR}=0.80,95 \% \mathrm{CI}=0.64$ to 1.00$)$, bus $(\mathrm{OR}=0.81$, $95 \% \mathrm{CI}=0.67$ to 0.97$)$ and subway $(\mathrm{OR}=0.78,95 \%$ $\mathrm{CI}=0.65$ to 0.95$)$ commuters had a lower risk of overall obesity. After adjusting for $\mathrm{PM}_{10}$, cycling $(\mathrm{OR}=0.37,95 \%$ $\mathrm{CI}=0.20$ to $\left.0.68, P_{\text {interaction }}=0.007\right)$ and bus $(\mathrm{OR}=0.58$, $95 \% \mathrm{CI}=0.36$ to $0.94, P_{\text {interaction }}=0.132$ ) commuters still had a lower risk of overall obesity in the analysis of the men. While in the female group, no significant association was observed between commuting mode and overall
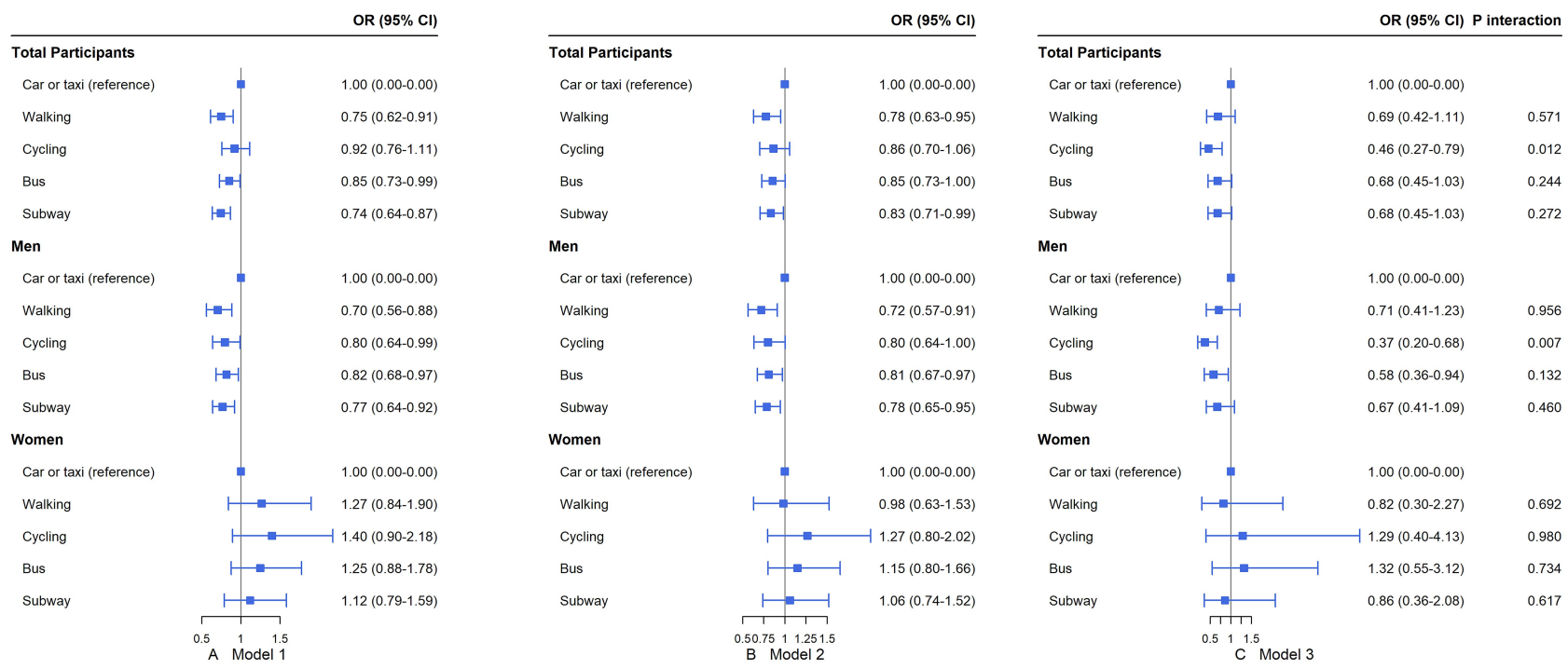

Figure 3 Association of commuting mode with overall obesity, stratified by gender $(n=10,524)$. Model I: unadjusted. Model 2: adjusted for age, gender, education, commuting time per day, self-reported work stress, physical activity frequency and intensity, sleep duration, smoking status, alcohol consumption status, proportion of meat and vegetable intake, dietary preferences and medical history of hypertension and diabetes. Model 3: adjusted for the factors in Model $2+\mathrm{PM}_{10}$. 

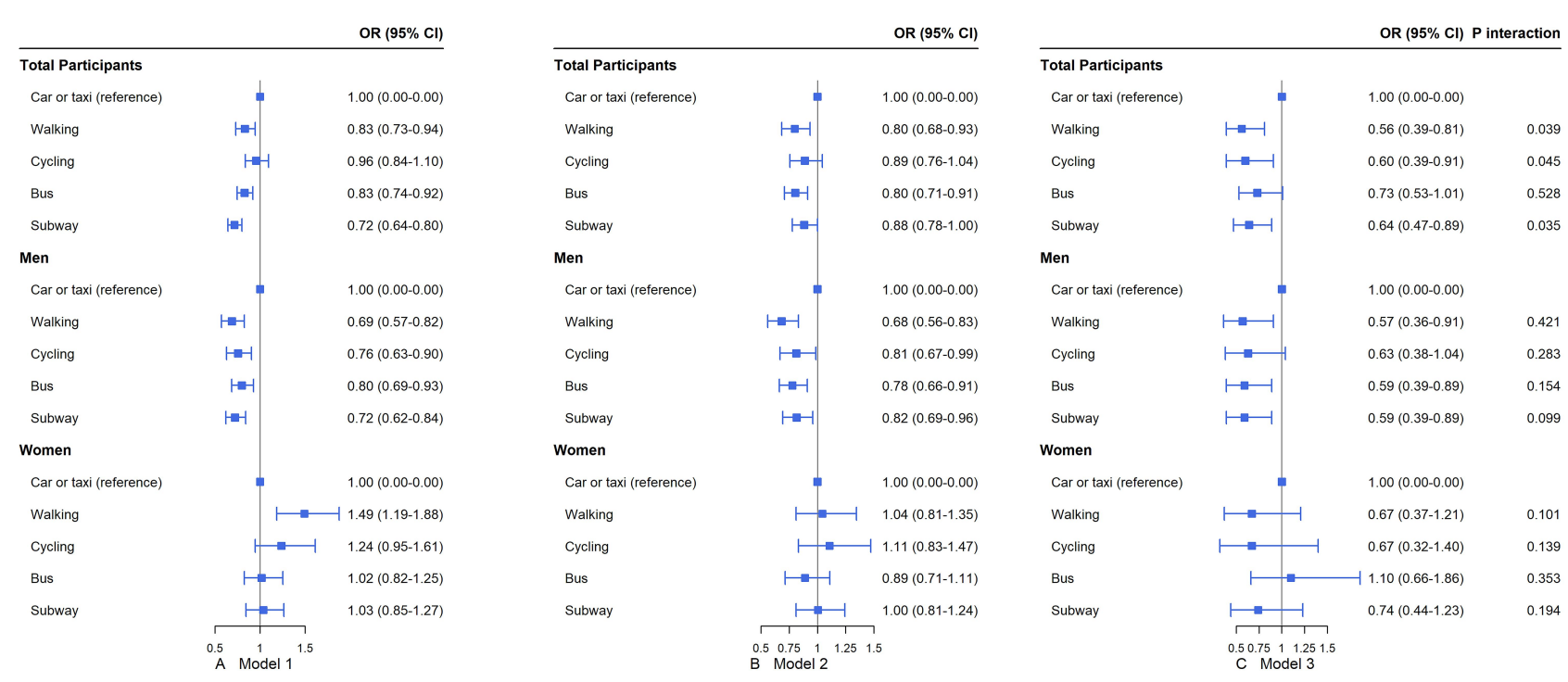

Figure 4 Association of commuting mode with abdominal obesity stratified by gender $(n=10,524)$. Model I: unadjusted. Model 2: adjusted for age, gender, education, commuting time per day, self-reported work stress, physical activity frequency and intensity, sleep duration, smoking status, alcohol consumption status, proportion of meat and vegetable intake, dietary preferences and medical history of hypertension and diabetes. Model 3: adjusted for the factors in Model $2+$ PM 10 .

obesity in the fully adjusted model. Figure 4 shows the associations of commuting mode with abdominal obesity after adjusting for potential confounders. Similarly, in fully adjusted model, walking ( $\mathrm{OR}=0.57,95 \% \mathrm{CI}=0.36$ to $\left.0.91, P_{\text {interaction }}=0.421\right)$, bus $(\mathrm{OR}=0.59,95 \% \mathrm{CI}=0.39$ to $\left.0.89, P_{\text {interaction }}=0.154\right)$ and subway $(\mathrm{OR}=0.59,95 \%$ $\mathrm{CI}=0.39$ to $\left.0.89, P_{\text {interaction }}=0.099\right)$ commuters still had a lower risk of abdominal obesity in the analysis of the men. No significant associations were observed between commuting mode and abdominal obesity in women. Across all models, compared with car or taxi commuters, bus commuters were always associated with a lower risk of overall and abdominal obesity in men. We observed significant interactions between exposure to $\mathrm{PM}_{10}$ $\left(P_{\text {interaction }}=0.007\right)$ and cycling, $\mathrm{SO}_{2}\left(P_{\text {interaction }}=0.0399\right)$ and walking on overall obesity in men. Exposure to $\mathrm{SO}_{2}$ $\left(P_{\text {interaction }}=0.0408\right)$ and bus, $\mathrm{SO}_{2}\left(P_{\text {interaction }}=0.0418\right)$ and subway had an interact effect on overall obesity in women. Exposure to $\mathrm{O}_{3}\left(P_{\text {interaction }}=0.0331\right)$ and walking had an interact effect on abdominal obesity in men. The results of other pollutants were different from $\mathrm{PM}_{10}$ (Table S3 and $\underline{\mathrm{S} 4})$. After adjusting for $\mathrm{PM}_{2.5}$, cycling (OR=0.50, 95\% $\mathrm{CI}=0.26$ to $\left.0.97, \quad P_{\text {interaction }}=0.1351\right)$ commuters had a lower risk of overall obesity in the analysis of the men. After adjusting for $\mathrm{SO}_{2}$, subway $(\mathrm{OR}=0.52,95 \% \mathrm{CI}=0.30$ to $\left.0.91, P_{\text {interaction }}=0.1151\right)$ commuters had a lower risk of overall obesity in the analysis of the men, while bus $\left(\mathrm{OR}=3.48,95 \% \mathrm{CI}=1.12\right.$ to $\left.10.85, P_{\text {interaction }}=0.0408\right)$ and subway $\left(\mathrm{OR}=3.17,95 \% \mathrm{CI}=1.03\right.$ to $9.75, \quad P_{\text {interaction }}$
$=0.0418)$ commuters had a higher risk of overall obesity in women. After adjusting for $\mathrm{O}_{3}$, walking $(\mathrm{OR}=0.45,95 \%$ $\mathrm{CI}=0.25$ to $\left.0.80, P_{\text {interaction }}=0.0738\right)$ and bus $(\mathrm{OR}=0.58$, $95 \% \mathrm{CI}=0.36$ to $\left.0.93, P_{\text {interaction }}=0.1386\right)$ commuters had a lower risk of overall obesity and walking $(\mathrm{OR}=0.43$, $95 \% \mathrm{CI}=0.27$ to $\left.0.68, P_{\text {interaction }}=0.0331\right)$ commuters had a lower risk of abdominal obesity in the analysis of the men.

The results from the sensitivity analyses of subsamples of leisure-time physical activity frequency or intensity were similar (Table S5-S8). In the physical activity frequency or intensity subsamples, walking, cycling and bus were always associated with a lower risk of obesity in the lower level of physical activity frequency or intensity.

\section{Discussion}

Commuting by walking, cycling, bus or subway was associated with a lower risk of obesity, no matter overall or abdominal obesity. However, bus was associated with the lowest risk of obesity, regardless of whether overall or abdominal obesity was being analyzed in male employees. These results revealed that active commuting and public commuting can be seen as a form of daily physical activity. ${ }^{32}$ Moreover, compared with commuting by car or taxi, those who travelled by active commuting (walking) or public commuting (bus or subway) had a lower risk of abdominal obesity, and this association was especially strong for men. Comprehensively adjusting for confounders and additionally adjusting for the impacts of the air 
pollutants did not attenuate the observed associations. The largest and most significant associations were observed for bus commuters versus car or taxi commuters. These results validate findings from other studies that show that active commuting or public commuting are associated with a lower risk of obesity. ${ }^{30,33-35}$

The prevalence of abdominal obesity in the working population was approximately three times that of overall obesity. To some extent, this finding reflects the trend of obesity in China in recent years. ${ }^{36,37} \mathrm{We}$ found that the association between active commuting and obesity was only present in men. In this study, women have lower prevalence of obesity, we did not find a significant association between commuting mode and obesity in women. Previous studies showed that stress is positively correlated with obesity. ${ }^{38}$ In this study, men reported higher self-reported work stress than women, which partly explains the higher prevalence of obesity in men than women. The gender difference in the association between commuting mode and obesity found in this study warrants further research.

Existing studies assessing the relationship between commuting mode and obesity have yielded varied results. Flint et $\mathrm{al}^{26}$ reported an association between active commuting and obesity. Commuting modes and leisure-time physical activities were associated with cardiovascular risk factors in previous studies ${ }^{23,39,40}$ However, few studies have previously reported the relationship between commuting mode and obesity after adjusting for air pollutants. The results of our study showed that the probability of experiencing obesity in people who commuted by walking, cycling, bus or subway was lower than that of those who commuted by car or taxi to work. Our findings are consistent with those of previous studies. ${ }^{24,34}$

This study explored the relationships between commuting mode and overall and abdominal obesity using a large, representative dataset from the working population in Beijing, China. The results of this study showed a robust, significant association between commuting mode and both overall and abdominal obesity. Our results suggested that different air pollutants had different effects on commuting mode and obesity. The interaction between air pollutants and commuting modes varies among air pollutants. The results of this study can only indicate that air pollutants may have an impact on obesity, which needs further study in the future.

\section{Strengths and Limitations}

To observe more robust results, we used two distinct obesity definitions to investigate the association between commuting mode and obesity outcomes. In this way, we reduced the limitation of using BMI to define obesity and addressed the concerns of the effect of WC. An increasing number of office workers suffer from abdominal obesity, rather than overall obesity, due to sedentary behavior and lack of physical activity.

This study has several limitations. As one of the most important confounding factors, we did not have information on dietary energy intake. To reduce bias, we adjusted some diet-related factors such as excessive meat intake, excessive edible oil intake, excessive salt intake and excessive sweet food intake in daily diet. In addition, sedentary behavior is a potential confounder for obesity. However, we did not have data on sedentary behavior. The third limitation is that the information about home address was lacking in our research, and the concentration of air pollutants in the subjects in this study was based on monitoring stations near the workplace rather than on more precise personal exposure to air pollutants. Further studies should measure individual exposure to air pollutants for more accurate results.

\section{Perspective}

The results showed that, compared with car or taxi commuting, active or public commuting was associated with a significantly lower risk of obesity. The findings in our study support the idea that efforts to increase bus commuting should be addressed as a strategy to prevent and reduce the prevalence of obesity, especially among male workers.

\section{Ethics Statement}

The research was approved by the Ethics Committee of Capital Medical University (NO: 2013SY26) and conducted in accordance with the Declaration of Helsinki. Written informed consent was obtained from all the participating subjects prior to data collection.

\section{Acknowledgments}

We sincerely thank the medical personnel who participated in the data collection and management in the physical checkup department of the Beijing physical examination center. 


\section{Funding}

This study was partially supported by the National Natural Science Foundation of China (serial number: 81530087, 81773542).

\section{Disclosure}

The authors declare that the research was conducted in the absence of any commercial or financial relationships that could be construed as a potential conflict of interest. The authors report no conflicts of interest for this work.

\section{References}

1. Lu J, Bi Y, Ning G. Curbing the obesity epidemic in China. Lancet Diabetes Endocrinol. 2016;4(6):470-471. doi:10.1016/S22138587(16)30007-9

2. Wang Y, Wang L, Qu W. New national data show alarming increase in obesity and noncommunicable chronic diseases in China. Eur J Clin Nutr. 2017;71(1):149-150. doi:10.1038/ejen.2016.171

3. Aroor AR, Jia G, Sowers JR. Cellular mechanisms underlying obesity-induced arterial stiffness. Am J Physiol Regul Integr Comp Physiol. 2018;314(3):R387-R398.

4. Chen WW, Gao RL, Liu LS, et al. China cardiovascular diseases report 2015: a summary. J Geriatr Cardiol. 2017;14(1):1-10.

5. Chen Y, Copeland WK, Vedanthan R, et al. Association between body mass index and cardiovascular disease mortality in east Asians and south Asians: pooled analysis of prospective data from the Asia Cohor Consortium. BMJ. 2013;347(oct01 1):f5446. doi:10.1136/bmj.f5446

6. Carmienke S, Freitag MH, Pischon T, et al. General and abdominal obesity parameters and their combination in relation to mortality: a systematic review and meta-regression analysis. Eur J Clin Nutr. 2013;67(6):573-585. doi:10.1038/ejcn.2013.61

7. Tian Y, Jiang C, Wang M, et al. BMI, leisure-time physical activity, and physical fitness in adults in China: results from a series of national surveys, 2000-14. Lancet Diabetes Endocrinol. 2016;4 (6):487-497. doi:10.1016/S2213-8587(16)00081-4

8. Wang M, Wen X, Zhang Y, Jiang C, Wang F. Is economic environment associated with the physical activity levels and obesity in Chinese adults? A cross-sectional study of 30 regions in China. BMC Public Health. 2017;17(1):701. doi:10.1186/s12889-017-4699-4

9. Dai L, Bind MA, Koutrakis P, et al. Fine particles, genetic pathways, and markers of inflammation and endothelial dysfunction: analysis on particulate species and sources. J Expo Sci Environ Epidemiol. 2016;26(4):415-421. doi:10.1038/jes.2015.83

10. Barrea L, Savastano S, Di Somma C, et al. Low serum vitamin D-status, air pollution and obesity: a dangerous liaison. Rev Endocr Metab Disord. 2017;18(2):207-214. doi:10.1007/s11154-016-9388-6

11. Song C, Wu L, Xie Y, et al. Air pollution in China: status and spatiotemporal variations. Environ Pollut. 2017;227:334-347. doi:10.1016/j.envpol.2017.04.075

12. Fang X, Li R, Xu Q, Bottai M, Fang F, Cao Y. A two-stage method to estimate the contribution of road traffic to $\mathrm{PM}_{2.5}$ concentrations in Beijing, China. Int J Environ Res Public Health. 2016;13(1):124. doi:10.3390/ijerph13010124

13. Carr LJ, Leonhard C, Tucker S, Fethke N, Benzo R, Gerr F. Total worker health intervention increases activity of sedentary workers. Am J Prev Med. 2016;50(1):9-17. doi:10.1016/j.amepre.2015.06.022

14. McPhee JS, French DP, Jackson D, Nazroo J, Pendleton N, Degens H. Physical activity in older age: perspectives for healthy ageing and frailty. Biogerontology. 2016;17(3):567-580. doi:10.1007/ s10522-016-9641-0
15. Street SJ, Wells JC, Hills AP. Windows of opportunity for physical activity in the prevention of obesity. Obes Rev. 2015;16(10):857-870. doi:10.1111/obr.12306

16. Norwood P, Eberth B, Farrar S, Anable J, Ludbrook A. Active travel intervention and physical activity behaviour: an evaluation. Soc Sci Med. 2014;113:50-58. doi:10.1016/j.socscimed.2014.05.003

17. Yang X, Jia X, Dong W, et al. Cardiovascular benefits of reducing personal exposure to traffic-related noise and particulate air pollution: a randomized crossover study in the Beijing Subway system. Indoor Air. 2018;28(5):777-786. doi:10.1111/ina.12485

18. Laeremans M, Dons E, Avila-Palencia I, et al. Short-term effects of physical activity, air pollution and their interaction on the cardiovascular and respiratory system. Environ Int. 2018;117:82-90. doi:10.1016/j.envint.2018.04.040

19. Sinharay R, Gong J, Barratt B, et al. Respiratory and cardiovascular responses to walking down a traffic-polluted road compared with walking in a traffic-free area in participants aged 60 years and older with chronic lung or heart disease and age-matched healthy controls: a randomised, crossover study. Lancet (London, England). 2018;391 (10118):339-349.

20. Zhang X, Zhao H, Chow WH, et al. Population-based study of traffic-related air pollution and obesity in Mexican Americans. Obesity (Silver Spring). 2020;28(2):412-420. doi:10.1002/ oby. 22697

21. Cui Y, Sun Q, Liu Z. Ambient particulate matter exposure and cardiovascular diseases: a focus on progenitor and stem cells. J Cell Mol Med. 2016;20(5):782-793. doi:10.1111/jcmm. 12822

22. Wei Y, Zhang JJ, Li Z, et al. Chronic exposure to air pollution particles increases the risk of obesity and metabolic syndrome: findings from a natural experiment in Beijing. FASEB j. 2016;30 (6):2115-2122. doi:10.1096/fj.201500142

23. Celis-Morales CA, Lyall DM, Welsh P, et al. Association between active commuting and incident cardiovascular disease, cancer, and mortality: prospective cohort study. BMJ. 2017;357:j1456. doi:10.1136/bmj.j1456

24. Steell L, Garrido-Mendez A, Petermann F, et al. Active commuting is associated with a lower risk of obesity, diabetes and metabolic syndrome in Chilean adults. J Public Health (Oxf). 2018;40:1-9.

25. Flint E, Cummins S, Sacker A. Associations between active commuting, body fat, and body mass index: population based, cross sectional study in the United Kingdom. BMJ. 2014;349(aug19 13): g4887. doi:10.1136/bmj.g4887

26. Flint E, Cummins S. Active commuting and obesity in mid-life: cross-sectional, observational evidence from UK Biobank. Lancet Diabetes Endocrinol. 2016;4(5):420-435. doi:10.1016/S22138587(16)00053-X

27. Calderon-Garciduenas L, Franco-Lira M, D'Angiulli A, et al. Mexico City normal weight children exposed to high concentrations of ambient PM2.5 show high blood leptin and endothelin-1, vitamin D deficiency, and food reward hormone dysregulation versus low pollution controls. Relevance for obesity and Alzheimer disease. Environ Res. 2015;140:579-592.

28. Schwartz J, Bind MA, Koutrakis P. Estimating causal effects of local air pollution on daily deaths: effect of low levels. Environ Health Perspect. 2017;125(1):23-29. doi:10.1289/EHP232

29. Sun Y, Song X, Han Y, et al. Size-fractioned ultrafine particles and black carbon associated with autonomic dysfunction in subjects with diabetes or impaired glucose tolerance in Shanghai, China. Part Fibre Toxicol. 2015;12:8. doi:10.1186/s12989-015-0084-6

30. Laverty AA, Webb E, Vamos EP, Millett C. Associations of increases in public transport use with physical activity and adiposity in older adults. Int J Behav Nutr Phys Act. 2018;15(1):31. doi:10.1186/ s12966-018-0660-x

31. Chen CM. Overview of obesity in Mainland China. Obes Rev. 2008;9 (Suppl 1):14-21. doi:10.1111/j.1467-789X.2007.00433.x 
32. Audrey S, Procter S, Cooper AR. The contribution of walking to work to adult physical activity levels: a cross sectional study. Int J Behav Nutr Phys Act. 2014;11(1):37. doi:10.1186/1479-5868-11-37

33. Turrell G, Hewitt BA, Rachele JN, Giles-Corti B, Busija L, Brown WJ. Do active modes of transport cause lower body mass index? Findings from the HABITAT longitudinal study. J Epidemiol Community Health. 2018;72(4):294-301. doi:10.1136/jech-2017-209957

34. Lu SR, Su J, Xiang QY, Zhang FY, Wu M. Active transport and health outcomes: findings from a population study in Jiangsu, China. J Environ Public Health. 2013;2013:624194. doi:10.1155/2013/624194

35. Webb E, Netuveli G, Millett C. Free bus passes, use of public transport and obesity among older people in England. J Epidemiol Community Health. 2012;66(2):176-180. doi:10.1136/jech.2011.133165

36. Adair LS, Gordon-Larsen P, Du SF, Zhang B, Popkin BM. The emergence of cardiometabolic disease risk in Chinese children and adults: consequences of changes in diet, physical activity and obesity. Obes Rev. 2014;15(Suppl 1):49-59. doi:10.1111/obr.12123
37. Zhang L, Wang Z, Wang X, et al. Prevalence of overweight and obesity in China: results from a cross-sectional study of 441 thousand adults, 2012-2015. Obes Res Clin Pract. 2020;14(2):119-126. doi:10.1016/j.orcp.2020.02.005

38. Cotter EW, Kelly NR. Stress-related eating, mindfulness, and obesity. Health Psychol. 2018;37(6):516-525. doi:10.1037/hea0000614

39. Lao XQ, Deng HB, Liu X, et al. Increased leisure-time physical activity associated with lower onset of diabetes in 44828 adults with impaired fasting glucose: a population-based prospective cohort study. Br J Sports Med. 2019;53(14):895-900.

40. Fan M, Yu C, Guo Y, et al. Effect of total, domain-specific, and intensity-specific physical activity on all-cause and cardiovascular mortality among hypertensive adults in China. $J$ Hypertens. 2018;36(4):793.

\section{Publish your work in this journal}

Diabetes, Metabolic Syndrome and Obesity: Targets and Therapy is an international, peer-reviewed open-access journal committed to the rapid publication of the latest laboratory and clinical findings in the fields of diabetes, metabolic syndrome and obesity research. Original research, review, case reports, hypothesis formation, expert opinion and commentaries are all considered for publication. The manuscript management system is completely online and includes a very quick and fair peer-review system, which is all easy to use. Visit http://www.dovepress.com/testimonials.php to read real quotes from published authors.

Submit your manuscript here: https://www.dovepress.com/diabetes-metabolic-syndrome-and-obesity-targets-and-therapy-journal 